\title{
TINJAUAN PELAKSANAAN PEKERJAAN TIMBUNAN TANAH PADA PROYEK PEMBANGUNAN LAPANGAN PARKIR JAKABARING SPORT CITY PALEMBANG
}

\author{
Yosieguspa ${ }^{*}$, Wirdattaul Humaeroh ${ }^{2}$ \\ Program Studi Teknik Sipil Fakultas Teknik \\ Universitas Islam Ogan Komering Ilir Kayuagung \\ *Corresponding Author, Email : Yosieguspa@yahoo.com
}

\begin{abstract}
ABSTRAK
Perkembangan dunia konstruksi yang semakin pesat, menjadikan banyak kegiatan pembangunan terjadi di hampir semua wilayah. Pemilihan alat berat yang akan dipakai untuk pekerjaan timbunan juga merupakan faktor yang sangat penting dalam keberhasilan suatu proyek. Alat berat yang dipakai juga haruslah benar sehingga proyek dapat berjalan lancar. Kesalahan dalam memilih alat berat dapat mengakibatkan menajement pelaksanaan proyek menjadi tidak efektif dan efisien. Untuk menghasilkan tenaga kerja dan terampil dan profesional, kita harus dapat membandingkan dan memahami antara praktek dan teori.
\end{abstract}

Kata Kunci : Konstruksi, Alat Berat, Tanah.

\section{PENDAHULUAN}

Dalam suatu perencanaan kontruksi dalam bidang teknik sipil (tanggul, bangunan, lahan parkir, jalan, jembatan dan lain-lain) tidak jarang ditemukan kondisi tanah asli yang labil sehinga daya dukung sangat rendah dan tidak memungkinkan untuk menahan suatu sistem pembebanan diatasnya.Hal ini dapat diatasi dengan melakukan timbunan tanah diatas lapisan tanah asli dengan tanah yang memiliki potensi daya dukung yang memadai.

Perkembangan dunia kontruksi yang semakin pesat, menjadikan banyak kegiatan pembangunan terjadi di hampir semua wilayah. Kebutuhan infrastruktur sebagai penunjang aktivitas manusia baik di bidang ekonomi, sosial, pendidikan, politik dan sebagainya menjadi dasar pembangunan, berkaitan dengan perkembangan kontruksi bangunan sipil tersebut melibatkan inovasi-inovasi yang terjadi pada sub bidang-bidang teknik sipil antara lain struktur, geoteknik, transportasi, menajemen kontruksi, keairan, lingkungan, planologi, serta sub bidang sipil lainnya yang saling terintegrasi.

Pemilihan alat berat yang akan dipakai untuk pekerjaan timbunan juga merupakan faktor yang sangat penting dalam keberhasilan suatu proyek. Alat berat yang dipakai juga haruslah benar sehingga proyek dapat berjalan lancar. Kesalahan dalam memilih alat berat dapat mengakibatkan menajement pelaksanaan proyek menjadi tidak efektif dan efisien.

Untuk menghasilkan tenaga kerja dan terampil dan profesional, kita harus dapat membandingkan dan memahami antara praktek dan teori.Salah satunya adalah diadakan kerja raktek (KP).Kerja praktek adalah salah satu usaha menunjang mahasiswa untuk memahami, membandingkan serta mengembangkan teori yang diperoleh dibangku perkuliahan.Atas dasar tersebut penulis mengangkat judul laporan kerja praktek "Tinjauan Pelaksanaan Pekerjaan Timbunan Tanah pada Proyek Pembangunan Lapangan Parkir Jakabaring Sport City - Palembang”. Yang menjadi masalah dalam penelitian ini adalah : 
a. Apa saja pekerjaan yang dilakukan dalam timbunan tanah?

b. Penentuan jenis dan tipe alat berat untuk penimbunan?

c. Alat berat apa yang digunakan dalam kegiatan tanah timbunan?

\section{TINJAUAN PUSTAKA}

Urugan tanah adalah suatu jenis pekerjaan yang bertujuan untuk memindahkan tanah (padas, merah, atau semi padas) dari satu tempat lokasi (sumber pengambilan tanah) ke tempat lokasi lain yang di inginkan sebanyak yang dibutuhkan agar tercapai bentuk dan ketinggian tanah yang diinginkan, antara lain sektor pertanian (sawah, ladang dan perkebunan), infrastruktur pembangunan (pondasi bangunan) dan kerajinan (gerabah, tembikar, pot, genteng dan batu bata). Dengan memakai acuan perhitungan ritase atau pun $\mathrm{m}^{3}$.

Timbunan dapat digunakan sebagai lapis penopang untuk meningkatkan daya dukung tanah dasar, juga digunakan didaerah saluran air dan lokasi serupa, timbunan atau urugan dibagi dalam 2 macam sesuai dengan maksud penggunaannya yaitu :

1. Timbunan biasa, adalah timbunan atau urugan yang digunakan untuk pencapaian elevasi akhir subgrade yang dinyatakan dalam gambar perencanaan tanpa maksud khusus lainnya. Timbunan biasa ini juga digunakan untuk penggantian material exsisting subgrade yang tidak memenuhi syarat.

1.1 Timbunan yang di klasifikasikan sebagai timbunan biasa harus terdiri dari tanah yang disetujui oleh pengawas yang memenuhi syarat untuk digunakan dalam pekerjaan permanen.

1.2 Bahan yang tidak termasuk tanah yang plastisitasnya tinggi, yang diklasifikasi sebagai A-7-6 dari persyaratan (AASHTO M 145) atau sebagai CH dalam sistem klasifikasi “ Unified atau Casagrande”. Sebagai tambahan, urugan ini harus memiliki CBR yang tak kurang dari $6 \%$ bila diuji dengan (AASHTO T 193).

1.3 Tanah yang pengembangannya tinggi yang memiliki nilai aktif lebih besar dari 1,25 bila di uji dengan (AASHTO T 258), tidak boleh digunakan sebagai bahan timbunan. Nilai aktif diatur sebagai indeks plastisitas (PI) - (AASHTO T 90) dan presentase ukuran lempung (AASHTO T 88).

2. Timbunan pilihan, adalah timbunan atau urugan yang di gunakan untuk pencapaian elevasi akhir subgrade yang disyaratkan dalam gambar perencanaan dengan maksud khusus lainnya, misalnya untuk mengurangi tebal lapisan pondasi bawah, untuk memperkecil gaya lateral tekanan tanah dibelakang dinding penahan tanah talud jalan.

Bahan timbunan pilihan harus memenuhi persyaratan sebagai berikut:

a) Timbunan hanya boleh diklasifikasikan sebagai "timbunan pilihan" bila digunakan pada lokasi atau untuk maksud yang telah ditentukan atau disetujui secara tertulis oleh pengawas.

b) Timbunan yang diklasifikasikan sebagai timbunan pilihan harus terdiri dari bahan tanah berpasir (sandy clay) atau padas yang memenuhi persyaratan dan sebagai tambahan harus memiliki sifat tertentu tergantung maksud penggunanya.

Dalam segala hal, seluruh urugan pilihan harus memiliki CBR paling sedikit $10 \%$, bila diuji sesuai dengan (AASHTO T 193). 
Faktor-faktor utama yang harus diperhitungkan dalam desain timbunan adalah :

a. stabilitas timbunan

b. daya dukung timbunan

c. penurunan (settlement) timbunan

d. kemampuan melayani lalu-lintas (trafficability)

e. faktor lain, terutama permeabilitas.

\section{Aplikasi Tanah Timbunan}

Sesuai dengan kebutuhan dan spesifikasi di lapangan maka kegiatan timbunan tanah yang akan diberlakukan dalam pekerjaan penimbunan terdiri dari :

1. Timbunan tanah kembali dari galian

Yang dimaksud dalam pekerjaan timbunan tanah kembali dari hasil galian adalah kegiatan penimbunan baik untuk tanggul maupun untuk dibelakang bangunan dengan mempergunakan bahan timbunan dari hasil galian yang secara spesifikasi teknis bahan tersebut dapat dipertanggung jawabkan.Penimbunan dilaksanakan secara lapis perlapis dengan ketebalan hampir sesuai dengan spesifikasi alat yang digunakan. Bila tidak ada intruksi lain dari direksi maka penyedia jasa wajib menggunakan tanah hasil galian untuk timbunan tanah isian. Bila material tanah hasil galian bangunan tidak cukup maka kontraktor dibolehkan menggunakan tanah dari luar (borrow area) atas ijin Direksi.

2. Timbunan tanah dengan material (barrow area)

Yang dimaksud dengan ppekerjaan timbunan tanah dengan material dari barrow area adalah kegiatan penimbunan baik untuk tanggul maupun untuk dibelakang bangunan dengan memergunakan bahan timbunan dari galian pada suatu lokasi barrow dengan jenis dan kualitas tanah yang tertentu dan enyedia jasa mengeluarkan biaya untuk pengadaan material tanah timbunan tersebut.

3. Timbunan lolos air

Timbunan kembali lolos air harus ditempatkan berdasarkan garis, ketinggian dan ukuran sepeti ditunjukkan dalam gambar atau seerti arahan Direksi. Material harus ditangani dan diletakkan sedemikian rupa untuk menghadiri segregasi. Timbunan kembali lolos air harus ditimbun secara lapis horizontal dengan ketebalan tidak lebih dari 50 (lima puluh) $\mathrm{cm}$ sebelum dipadatkan dan dipadatkan secara menyeluruh dengan alat pemadat kapasitas 10 ton (vibratory roller) atau berdasarkan kepadatan dari uji timbunan yang telah mendapatkan persetujuan dari Direksi. Material filter harus terdiri dari materal yang layak, awet, pasir dan kerikil berdegradasi baik dengan ukuran partikel kurang dari $8 \mathrm{~cm}$. juga material tidak boleh mengandung fraksi lolos saringan no.4 dalam jumlah lebih dari 50\% begitu juga lolos saringan no.200 tidak lebih atau kurang dari $10 \%$.

Sebelum melakukan pekerjaan penimbunan, ada beberapa tes yang harus dilakukan, yaitu :

1. Kepadatan Lapangan (Field Density)

2. Permeabilitas Lapangan (Field Permeability)

3. Berat Jenis (Sppesific Grafity) 


\section{Kadar Air (Water Content) \\ 5. Konsistensi (Consistency/Atterberg Limit) \\ 6. Gradasi (Gradation) Lapangan dan Laboraturium \\ 7. Kepadatan Laboraturium (Proctor Compaction)}

\section{Stabilitas Timbunan}

Stabilitas timbunan sering berubah dari waktu ke waktu.Hal tersebut makin nyata apabila menyangkut tanah kohesif. Dalam banyak kasus, pada saat pembangunan akan terjadi kenaikan tegangan air pori, baik pada tanah timbunan maupun tanah pondasi. Sesuai dengan berjalannya waktu, tegangan air pori pada tanah timbunan dapat makin meningkat atau menurun, sedangkan pada tanah pondasi cenderung menurun. Oleh karena itu, menjelang akhir masa pembangunan, faktor keamanan stabilitas lereng timbunan sering mempunyai nilai paling rendah. Apabila untuk timbunan digunakan lempung yang telah mengalami konsolidasi (overconsolidated clays), dibawah lereng sering timbul tegangan air pori yang dapat mengakibatkan keruntuhan lereng beberapa tahun kemudian.

Tabel 1 Kemiringan tipikal lereng timbunan

\begin{tabular}{|l|c|c|}
\hline \multicolumn{1}{|c|}{ JENIS TANAH COEMINGAN (V:H) } \\
\hline Batuan keras (hard rock fill) & $1,5: 1-1: 1$ & \\
Batuan lunak (weak rock fill) & $1: 2-1: 1,25$ & \\
Kerikil & $1: 2-1: 1,5$ & \\
Pasir & $1: 2,5-1: 1,5$ & \\
Lempung & KE $1: 2,5-1: 1,5$ & \\
\hline
\end{tabular}

(Sumber: Horner, 1988)

Sifat-sifat tanah timbunan akan berubah dari waktu ke waktu; misal, akibat konsolidasi atau peningkatan kadar air. Pada saat menetapkan daya dukung, hal tersebut perlu di perhatikan.

Pada disain jalan raya, jalan kereta api dan lapang terbang, daya dukung atau kekuatan timbunan biasanya dinyatakan dengan CBR (California bearing ratio) atau modulus reaksi tanah, sedangkan pada disain pondasi, daya dukung timbunan sering dinyatakan dengan hasil pengujian pelat beban (plate bearing test) atau triaksial

.Penurunan (settlement) pada timbunan dapat diakibatkan oleh penurunan, baik pada timbunan sendiri atau pada tanah asli. Apabila timbunan terdiri atas tanah permeable, konsolidasi akan terjadi selama pelaksanaan dan dapat dipercepat dengan menambah timbunan. Namun demikian, konsolidasi tanah timbunan yang mempunyai permeabilitas rendah dapat berlangsung beberapa minggu atau beberapa tahun setelah pembangunan, kecuali apabila dilakukan percepatan, disamping dapat memperbaiki stabilitas.Perbedaan penurunan sering terjadi pada timbunan disekitar bangunan, karena urugan dekat bangunan umumnya tidak menurun secara bersamaan dengan urugan dibagian lain, disamping urugan dekat bangunan lebih sulit didapatkan. Perbedaan tersebut dapat dikurangi melalui penggunaan tanah urugan husus misal, kerikil persoalan yang sama dapat dijumpai apabila timbunan mempunyai ketinggian yang sangat berbeda. 
Usaha-usaha tersebut mencakup salah satu atau gabungan beberapa teknik sebagai berikut :

a. Memperkecil sudut kemiringan lereng (memperlebar dasar timbunan).

b. Membangun beban kontra (berm)di depan tumit lereng.

c. Menggunakan tanah urugan berkekuatan tinggi.

d. Meningkatkan kekuatan, baik dengan pemadatan dan pengeringan atau stabilitas tanah urugan (dengan kapur atau semen).

e. Membuat lapisan drainase, untuk menurunkan tegangan air pori.

f. Memasang geotextile.

g. Membangun konstruksi penahan, baik sebagian atau seluruhnya.

h. Membuang atau mendorong (displacement) tanah yang lunak, baik sebagian maupun seluruhnya, dan menggantinya dengan tanah yang lebih baik.

i. Membuat parit yang lebar dan dalam serta mengisinya dengan tanah berbutir.

j. Memperbaiki tanah dengan cara pra-pembebanan (preloading), konsolidasi dinamis atau vibrofloatation.

k. Mengendalikan kecepatan pelaksanaan, agar tanah mempunyai waktu yang cukup untuk konsolidasi dan meningkatkan kekuatan.

1. Menggunakan beban ringan (misal abu terbang), agar timbunan menjadi lebih ringan.

m. Membuat drainase vertikal dan/atau lapisan drainase horizontal, agar dapat mempercepat pelepasan tegangan air pori, penurunan dan peningkatan kekuatan.

Untuk mendapatkan pondasi yang kokoh, mungkin diperlukan upaya penanganan yang ekstensif.Dalam praktek, kadang-kadang dialami bahwa tanah yang baik sebagai bahan timbunan, tetapi ternyata dinyatakan tidak baik.Hal tersebut dikarenakan spesifikasi menetapkan bahwa timbunan harus dapat melayani peralatan yang berat, misal heavy rubber-tyred scrapers.

\section{Tahapan-Tahapan Pekerjaan Timbunan}

Pekerjaan timbunan dilaksanakan pada bangunan yang sudah dikerjakan (pasangan batu atau beton) sudah cukup usia dan cukup kuat terhadap gangguan akibat pekerjaan timbunan dan pemadatan, atas persetujuan direksi. Pekerjaan timbunan dilaksanakan layer per layer dan dipadatkan. Ketebalan tiap layer maksimal adalah $0.20 \mathrm{~m}$. alat pemadat yang dipergunakan adalah hand stamper. Hand stamper dipergunakan pada bagian perbatasan antara bidang timbunan dan bidang struktur.

Pekerjaan timbunan tanah rondom juga dilakukan layer per layer dan dipadatkan sesuai dengan spesifikasi teknis. Semua material timbunan, baik dari hasil galian atau dari stock pile ataupun dari barrow area harus memenuhi syarat kualitas dan bebas dari bahanbahan organic seperti tonggak-tonggak kayu, semak belukar, rerumputan, akar-akaran dan sejenisnya, disamping itu juga harus bebas dari bongkahan batu cadas dengan diameter lebih dari $15 \mathrm{~cm}$ atau bahan-bahan lain yang diizinkan adalah material yang mempunyai sifat dan gradasi baik.

Bila kadar air material ditempat pengambilan lebih rendah dari kadar air optimum, maka harus dilakukan pembahasan material timbunan dilokasi pengambilan atau tempat dimana material timbunan dihampar sebelum dipadatkan. Gaya-gaya penahan berupa gaya 
gesekan, geseran ,lekatan,kekuatan geser tanah, dan harus kita periksa apakah ada permukaan gelincir yang dapat menggerakkan lereng tersebut, untuk mengukur stabilitas lereng, (Cannonica,L,1991)

Proses pelaksanaan: material diangkut/ditimbun kelokasi timbunan menggunakan tenaga manual. Material hasil galian yang oleh direksi dinyatakan tidak layak, tidak akan digunakan dan disingkirkan dari lokasi timbunan penghamparan/penimbunan digunakann lerlapis/perlayer dengan ketentuan min $20 \mathrm{~cm}$ tebal lapisan timbunan. Dilanjutkan dengan menyiramkan air dengan mesin pompa air disemburkan secara sporadis ke area timbunan sampai tingkat kepadatan sesuai permintaan direksi. Setelah dinyatakan cukup kering/air sudah benar-benar meresap diadakan pemadatan menggunakan hand stamper. Proses pemadatan dilakukan secar roll back baik dengan arah vertical atau horizontal bidang timbunan min system roll back (bolak-balik) dilanjutkan kelapisan berikutkan dengan system yang sama.

\section{Alat Berat Yang Digunakan Pada Timbunan Tanah}

\section{Alat Penggali}

Jenis alat ini dikenal juga dengan istilah excavator.Beberapa alat berat digunakan untuk menggali tanah dan batuan. Yang termasuk didalam kategori ini adalah front shovel, backhoe, dragline, dan clamshell.

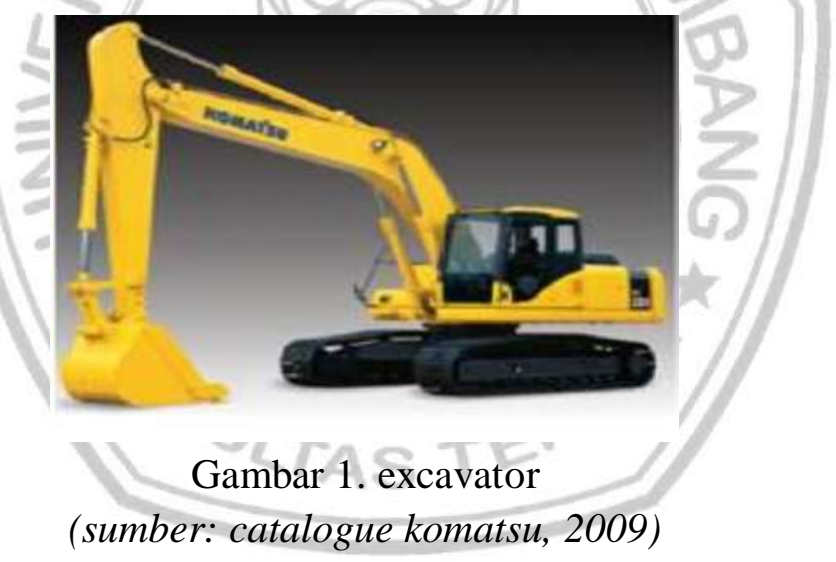

\section{Alat Pengangkut Material}

Untuk pengangkutan material lepas, (loose material) dengan jarak tempuh yang relative jauh, alat yang digunakan memerlukan alat lain yang membantu memuat material ke dalamnya.

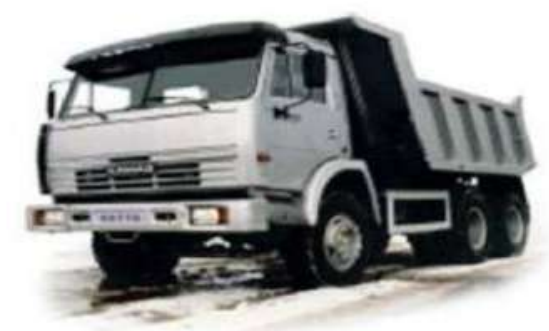

Gambar 2. dump truck

(sumber: gkodriders.files.wordpress.com, 2011) 


\section{Alat Perata Tanah (Grader)}

Berfungsi untuk meratakan pembukaan tanah secara mekanis, disamping itu grader dapat dipakai pula untuk keperluan lain misalnya untuk penggusuran tanah, pencampuran tanah, meratakan tanggul, pengurugan kembali galian tanah dan sebagainya.

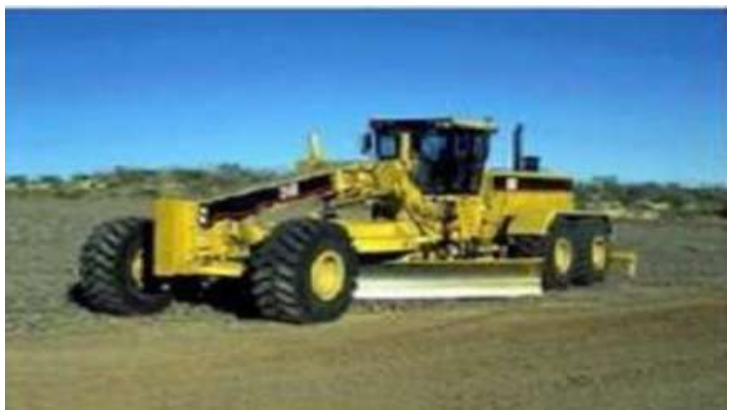

Gambar 3. motor grader

(sumber: wedhanto, 2009)

\section{Alat Pemuat Hasil Galian (Loader)}

Pada prinsipnya loader merupakan alat pembantu untuk mengangkut material dari tempat-tempat penimbunan kea lat pengangkut lain.

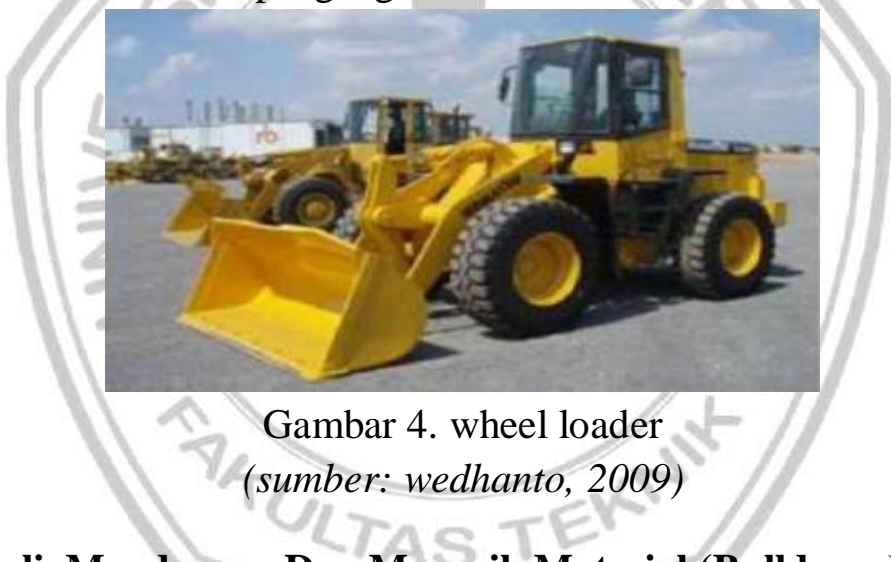

\section{Alat Untuk Menggali, Mendorong Dan Menarik Material (Bulldozer)}

Bulldozer adalah jenis peralatan kontruksi bertipe traktor menggunakan track/rantai serta dilengkapi dengan pisau (dikenal dengan blade) yang terletak didepan.

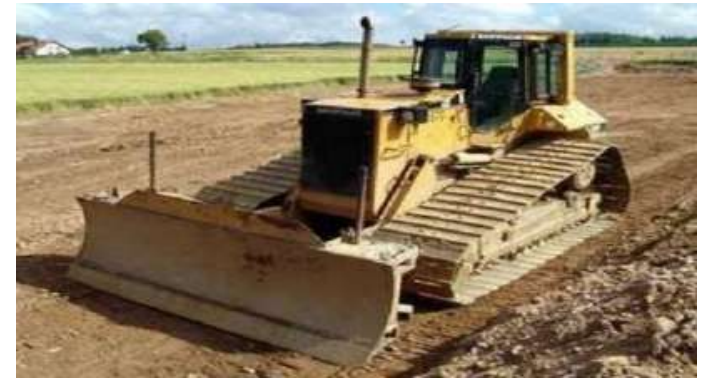

Gambar 5. Bulldozer

(sumber: wedhanto, 2009) 


\section{METODE PENELITIAN}

Metode penulisan dengan didasarkan pada:

- Tinjauan langsung ke lokasi proyek pekerjaan untuk melihat pelaksanaan pekerjaan di lapangan

- Mencari informasi dengan para pelaksana pekerja di lokasi pekerjaan, pemilik proyek dan pengawas

- Mengumpulkan data - data di literatur dan menganalisa bahan bacaan yang diperoleh.

\section{HASIL DAN PEMBAHASAN}

\section{Cara Pembayaran}

Cara pembayaran pada proyek ini menggunakan metode kontrak dimana system kontak ini menggunakan batas waktu tertentu, jumlah harga kontrak yang pasti dan tetap, serta semua resiko yang mungkin terjadi dalam pelaksanaan pekerjaan ditanggung pihak pelaksana/kontraktor.

\section{Pekerjaan Land Clearing}

Menghitung volume luas pembersihan lahan

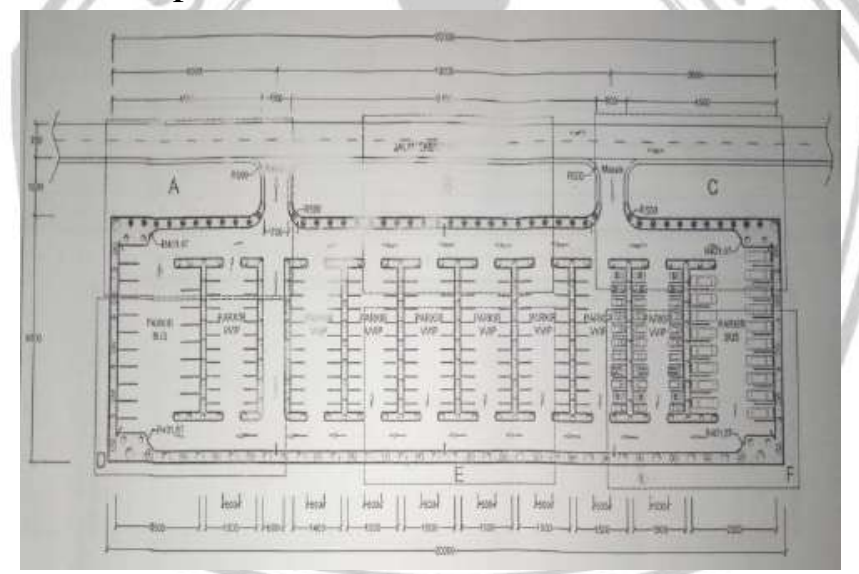

Gambar 6. Denah Lapangan Parkir

$\mathrm{V}=\mathrm{P} \times \mathrm{L}$

Ket : $\quad \mathrm{V}=$ Volume

$\mathrm{P}=$ Panjang

$\mathrm{L}=$ Lebar

$\mathrm{V}=\mathrm{P} \times \mathrm{L}$

$\mathrm{V}=204 \times 54$

$\mathrm{V}=11,016.00 \mathrm{~m}^{2}$ 


\section{Analisa harga satuan pembersihan lapangan}

Tabel 2. AHS Pembersihan Lapangan

\begin{tabular}{|c|c|c|c|c|c|c|}
\hline \multirow{2}{*}{$\begin{array}{c}\text { Uraian jenis } \\
\text { pekerjaan }\end{array}$} & Sat & Koeff. & $\begin{array}{c}\text { Harga sat (Rp) } \\
\text { bahan/upah }\end{array}$ & \multicolumn{2}{|c|}{ Jumlah harga Rp } & Jumlah harga (Rp) \\
bahan + upah & Bahan & Upah & \\
\hline \multicolumn{1}{|c|}{$\begin{array}{r}\text { 1 M2 PEMBERSIHAN \& PERATAAN } \\
\text { TANAH (SNI.Edisi Rev.2002) }\end{array}$} & & & \\
\hline $\begin{array}{c}\text { Tenaga } \\
\text { kerja : }\end{array}$ & & & & & & \\
\hline Pekerja & Oh & 0.1000 & $30,000.00$ & - & $3,000.00$ & \\
\hline Mandor & Oh & 0.0500 & $45,000.00$ & - & $2,250.00$ & \\
\hline Jumlah & & & & & $5,250.00$ & Rp. $5,250.00$ \\
\hline
\end{tabular}

\section{Menghitung Biaya Pembersihan Lahan}

Harga satuan $\mathrm{x}$ volume

Biaya pembersihan lahan $=$ Rp. $3,404.50,-x 11,016.00 \mathrm{~m}^{2}=$ Rp. $37,503,972.00,-$

\section{Analisa Data Produksi Bulldozer}

- Nama alat

$=$ Bulldozer

- Tipe alat

$=$ Komatsu D65WX-18

- Ukuran blade

$=\mathrm{L}=3,58 \mathrm{~m} ; \mathrm{H}=1,425 \mathrm{~m}$

- Status alat

$=$ Baik

- Factor blade

$=0,9$

- Efisiensi kerja

$=0,75$

- Jarak gusur

$=50 \mathrm{~m}$

- Kecepatan maju

$=5,533 \mathrm{~km} / \mathrm{jam}$

- Kecepatan mundur

$=6,633 \mathrm{~km} / \mathrm{jam}$

- Waktu ganti persneling

$=0,11$ menit

a. Produksi per siklus

$$
\begin{aligned}
\mathrm{q} & =\mathrm{L} \times \mathrm{H}^{2} \times \mathrm{a} \\
& =3,58 \times 1,425^{2} \times 0,9=6,54 \mathrm{~m}^{3}
\end{aligned}
$$

b. Waktu siklus $(\mathrm{cm})$

Kecepatan maju $\quad=5,533 \mathrm{~km} / \mathrm{jam}=92,216 \mathrm{~m} / \mathrm{menit}$

Kecepatan mundur $=6,633 \mathrm{~km} / \mathrm{jam}=110,55 \mathrm{~m} / \mathrm{menit}$

Waktu persneling $=0,11$ menit

$\mathrm{Cm}=\frac{D}{E} \mathrm{x} \frac{D}{R}+\mathrm{Z}$, menit

$\mathrm{Cm}=\frac{50}{92,216} \times \frac{50}{110,55}+0,11$

$\mathrm{Cm}=0,355$ menit 
c. Produktifitas Bulldozer

$$
\begin{aligned}
& \mathrm{Q}=\frac{\mathrm{qx} 60 x \mathrm{x} x \mathrm{fahtorkonversitanah}}{} \\
& =\frac{6,54 \times 60 \times 0,75 \times 1,25}{0,355} \\
& =1.036,267 \mathrm{~m}^{3} / \mathrm{jam}
\end{aligned}
$$

d. Site out put per hari

Dalam satu hari alat bekerja selama 8 jam

$=8 \times 1036,267=8.290,14 \mathrm{~m}^{3} / \mathrm{hari}$

e. Jumlah bulldozer yang dibutuhkan

$$
\begin{aligned}
& =\frac{\text { siteoutputexcavator }}{\text { siteoutputperhari }} \\
& =\frac{598,628}{9290,14}=0,072 \approx 1 \text { unit }
\end{aligned}
$$

\section{KESIMPULAN}

Setelah melakukan penelitian di lapangan pada proyek pembangunan lapangan parkir Jakabaring sport city, penulis dapat mengambil kesimpulan bahwa:

1. Pada saat mengerjakan penimbunan excavator yang digunakan untuk mengerjakan penimbunan mengalami kerusakan selama beberapa hari dan membutuhkan perbaikan, sehingga pekerjaan penimbunan menjadi terhambat.

2. Keadaan cuaca pada saat pengerjaan timbunan sangat menghambat pekerja untuk bekerja dan mengakibatkan terjadinya genangan air di area lokasi tersebut.

\section{DAFTAR PUSTAKA}

Ahadi.(2017) Cara Menghitung Luas Pembersihan Lahan [Internet]. Tersedia Dalam http://www.ahadi.id/cara-menghitung-luas-Pembersihan-Lahan [Diakses pada tanggal 09 Maret 2019]

Arikunto, Suharsimi,1998, Prosedur Penelitian Suatu Pendekatan Praktek, dalam https://jurnal.univpgri-palembang.ac.id/index.php/deformasi/article/view/915/767

Cannonica,L,2007, Memahami Mekanika Tanah Dalam https://jurnal.univpgripalembang.ac.id/index.php/deformasi/article/view/2323/2121

Iswantoro, Joko. 2003. Tinjauan Potensi Tanah Timbunan Dilihat dari Sifat-Sifat Fisik serta Daerah Penyebarannya di Kabupaten Lampung Tengah. Fakultas Teknik Universitas Lampung

Johan K ,dkk,2004, Sifat-sifat Fisik dan Geoteknik Tanah, Dalam https://jurnal.univpgripalembang.ac.id/index.php/deformasi/article/view/2323/2121

Jonizar, dkk, Pedoman Penulisan Pelaksanaan Kerja Praktek dan Tugas Akhir. Tunas Gemilang Press, Palembang, 2011.

Maman, Sudarman. (2016) Pengertian dan Pengerjaan Land Clearing dan cara Pelaksanaan [Internet]. Tersedia Dalam https://www.situstekniksipil.com/2017/11 /pengertian- Pekerjaan-Land-Clearing-dan.html?m=1 [Diakses pada tanggal 09 Maret 2019] 
Muslikah, siti.2012. Struktur Galian Dan Timbunan Tanah. Hal.42-43. Pada tanggal 02 November.

Rostiyanti Susy Fatena, Alat Berat Untuk Proyek Kontruksi Edisi Kedua. Rincka Cipta, Jakarta, 2008.

Rostiyanti. (2009) Macam-macam Alat Berat dan Fungsinya [Internet]. Tersedia Dalam :http://forek-pembangunan.blogspot.com/2014/02/macam-macam-alat-berat-danfungsinya.html?m=1 [Diakses pada tanggal 02 November 2018]

Sandi, Rinto. (2014). Kayuagung: Tinjauan Pelaksanaan Proyek Peningkatan Jalan Dalam Kota Kayuagung 1 Paket di Jalan Masjid Al Hidayah Kelurahan Sukadana Kecamatan Kota Kayuagung Kabupaten Ogan Komering Ilir. (15 November).

Sigit, Soehardi, 1999 (hal:6), Pengantar Metodologi Penelitian. dalam https://jurnal.univpgri-palembang.ac.id/index.php/deformasi/article/view/915/767

Team Divisi Kemahasiswaan. (2010) Sistematika Laporan KP [Internet]. Tersedia dalam http://if.mifa.uns.ac.id/new/wp-content/uploads/2016/08/sisematika-laporanKP.pdf 